\title{
Recent advances in the vibrational spectroscopic diagnosis of non-small cell lung cancer
}

\author{
Declan O'Dea \\ Technological University Dublin, declan.odea@tudublin.ie \\ Fiona Lyng \\ Technological University Dublin, fiona.lyng@tudublin.ie \\ Siobhan Nicholson \\ St James's Hospital, Dublin
}

See next page for additional authors

Follow this and additional works at: https://arrow.tudublin.ie/radart

Part of the Analytical, Diagnostic and Therapeutic Techniques and Equipment Commons, Diseases Commons, Oncology Commons, and the Radiation Medicine Commons

\section{Recommended Citation}

Declan O'Dea, Fiona M. Lyng, Siobhan Nicholson, Finbar O'Connell, Aoife Maguire, Alison Malkin, Recent advances in the vibrational spectroscopic diagnosis of non-small cell lung cancer, Vibrational Spectroscopy, Volume 104, 2019, 102946, ISSN 0924-2031, DOI: 10.1016/j.vibspec.2019.102946.

This Article is brought to you for free and open access by the Radiation and Environmental Science Centre at ARROW@TU Dublin. It has been accepted for inclusion in Articles by an authorized administrator of ARROW@TU

Dublin. For more information, please contact

arrow.admin@tudublin.ie, aisling.coyne@tudublin.ie, gerard.connolly@tudublin.ie.

Funder: Technological University Dublin






\section{Authors}

Declan O'Dea, Fiona Lyng, Siobhan Nicholson, Finbar O'Connell, Aoife Maguire, and Alison Malkin

This article is available at ARROW@TU Dublin: https://arrow.tudublin.ie/radart/85 


\title{
Recent advances in the vibrational spectroscopic diagnosis of non-small cell lung cancer
}

\author{
Declan O’Dea $^{\mathrm{a}, \mathrm{b}, *}$, Fiona M. Lyng ${ }^{\mathrm{b}, \mathrm{c}}$, Siobhan Nicholson ${ }^{\mathrm{d}}$, Finbar O'Connell ${ }^{\mathrm{d}}$, Aoife Maguire ${ }^{\mathrm{d}}$, \\ Alison Malkin ${ }^{\mathrm{a}}$ \\ ${ }^{a}$ School of Biological and Health Sciences, Technological University Dublin, Dublin, Ireland \\ ${ }^{\mathrm{b}}$ Radiation and Environmental Science Centre, FOCAS Research Institute, Technological University Dublin, Dublin, Ireland \\ ${ }^{\text {c }}$ School of Physics \& Clinical \& Optometric Sciences, Technological University Dublin, Dublin, Ireland \\ ${ }^{\mathrm{d}}$ St James's Hospital, James's Street, Dublin 8, Ireland
}

\section{A R T I C L E I N F O}

\section{Keywords:}

Non-small cell lung carcinoma

Raman spectroscopy

Fourier transform infrared spectroscopy

Differential diagnosis

Cytology

\begin{abstract}
A B S T R A C T
Lung cancer is the leading cause of cancer deaths worldwide accounting for 1.69 million deaths in 2015. Studies have indicated a 5 year survival rate of $8 \%-15 \%$ in western countries, although a survival rate as low as $1 \%$ has been demonstrated for late stage diagnosis. With the advent of targeted therapies, it is imperative to accurately differentiate non-small cell lung cancer (NSCLC) subtypes in order to ensure efficacy of treatment for patients. Immunohistochemistry and molecular techniques for the diagnosis of NSCLC are increasingly part of the diagnostic algorithm and clinical work-up of lung cancer patients, however due to the limitation of small sample size, overlapping morphological features and molecular characterisation, differential diagnosis of NSCLC still proves challenging. Vibrational spectroscopy has shown promising results for the detection of a variety of cancers and a limited number of studies have focused on lung cancer. Yet to date there has been no published evaluation of vibrational spectroscopy on cytology bronchoscopy samples which may eliminate the necessity for an invasive biopsy procedure. Following an introduction to the epidemiology and etiological factors associated with NSCLC, currently used diagnostic methods and their limitations are presented. A thorough review of Raman and FTIR spectroscopic methods in lung cancer diagnosis is then presented. On review of the literature, vibrational spectroscopy offers an alternative or adjunct diagnostic method to be applied in bronchoscopy cytology samples.
\end{abstract}

\section{Lung cancer}

\subsection{Introduction to lung cancer}

With an estimated 2.1 million new cases and 1.76 million deaths in 2018 , lung cancer persists as the most common cancer worldwide, and represents the highest cancer incidence and mortality rates in both developed and less developed countries [1,2]. Studies have indicated a 5 year survival rate of $8 \%-15 \%$ in developed countries, although a survival rate as low as $1 \%$ has been reported for late stage diagnosis [3-5]. Global lung cancer incidence trends indicate that athough western regions such as Northern America and Europe have the highest rates of incidence, the rate of incidence is declining in these regions, while increasing in less developed regions [6,7]. These trends can be directly correlated with smoking prevalence, as cigarette smoking is responsible for $85 \%$ of lung cancer cases. Other risk factors for nonsmokers include passive cigarette smoking and air pollution [8].
Lung cancer is divided into two main categories, small cell lung cancer (SCLC) accounting for an estimated $13 \%-14 \%$ of cases, and nonsmall cell lung cancer (NSCLC), which is the most common form of lung cancer accounting for approximately $85 \%$ of cases [9-12]. Furthermore, NSCLC includes different histological subtypes including squamous cell carcinoma (SCC), adenocarcinoma (AC) and large cell carcinoma. AC is more prevalent in non-smokers and accounts for the largest portion of all lung cancer cases at $44 \%$, and accounting for approximately $26 \%$ of lung cancer cases, SCC is the second most common subtype [9]. An epidemiological study [13] examining sex differences in lung cancer incidence and survival reported that women are more commonly diagnosed at an earlier stage of lung cancer, and at an earlier age than men. The study also indicated that regardless of age and stage of the disease at diagnosis, women have an increased survival in comparison to men, and this is most evident with the AC subtype. Irrespective of sex, patient prognosis is dependent on the stage of the disease at diagnosis [14]. Table 1 illustrates the approximate 5 year

\footnotetext{
* Corresponding author at: FOCAS Research Institute, TU Dublin Kevin St, Dublin 8, Ireland.

E-mail address: declan.odea@mydit.ie (D. O’Dea).
} 
Table 1

Progression stage, estimated 5 year survival rate, and appropriate treatments for each stage of NSCLC [15-24].

\begin{tabular}{|c|c|c|c|}
\hline $\begin{array}{l}\text { Stage of } \\
\text { NSCLC }\end{array}$ & Progression stage & $\begin{array}{l}\text { Approximate } 5 \text { year } \\
\text { survival rate }(\%)\end{array}$ & Treatment \\
\hline Stage IA & Localised $(<3 \mathrm{~cm})$ & 75 & Lobectomy \\
\hline Stage IB & Localised $(3-5 \mathrm{~cm})$ & 55 & Lobectomy \\
\hline Stage IIA & Localised $(5-7 \mathrm{~cm})$ OR Spread to nearby lymph nodes $(<5 \mathrm{~cm})$ & 50 & Lobectomy/adjuvant chemotherapy \\
\hline Stage IIB & $\begin{array}{l}\text { Spread to nearby lymph nodes/diaphragm/mediastinal pleura/parietal } \\
\text { pericardium/bronchus }(5-7 \mathrm{~cm}) \text { OR no spreading and }>7 \mathrm{~cm}\end{array}$ & 40 & Lobectomy/adjuvant chemotherapy \\
\hline Stage IIIA & $\begin{array}{l}\text { Spread to local lymph nodes/heart/trachea/oesophagus/phrenic nerve/ } \\
\text { present in more than one lobe }(>7 \mathrm{~cm})\end{array}$ & $10-35$ & $\begin{array}{l}\text { Radiotherapy/chemotherapy/immunotherapy/ } \\
\text { tyrosine kinase inhibitors }\end{array}$ \\
\hline Stage IIIB & $\begin{array}{l}\text { Spread to lymph nodes of opposite lungOR spread to lymph nodes in the } \\
\text { mediastinum and one or more of the areas mentioned in stage IIIA or a main } \\
\text { blood vessel }\end{array}$ & $<5$ & $\begin{array}{l}\text { Radiotherapy/chemotherapy/immunotherapy/ } \\
\text { tyrosine kinase inhibitors }\end{array}$ \\
\hline Stage IV & $\begin{array}{l}\text { Metastasised to another body part, other lung, caused malignant pleural } \\
\text { effusion/pericardial effusion }\end{array}$ & $<5$ & $\begin{array}{l}\text { Combination of cytotoxic chemotherapies/ } \\
\text { palliative care/ tyrosine kinase Inhibitors }\end{array}$ \\
\hline
\end{tabular}

survival rates for different stages of NSCLC [15-19].

\subsection{Current treatment options}

Therapeutic strategies and patient management are dependent on the stage, subtype, and mutation status of the malignancy [25]. Patients diagnosed with early stage (stage I and stage II) lung cancer may avail of potentially curative treatment through surgical resection. Although patients with early stage lung cancer have a 5 year survival rate of over $70 \%$, and chemotherapy post-surgery has been shown to benefit some stage II patients, the risk of metastatic recurrence after surgery remains as high as $70 \%[12,14,26]$. However, over half of patients are diagnosed at advanced stage and are not eligible for surgical resection. Treatments available for advanced stage disease include platinum based chemotherapies, radiotherapy, immunotherapies and molecular targeted therapies, including tyrosine kinase inhibitors (TKIs) [15-19,27]. In recent years combining chemotherapy with the appropriate TKIs has been shown to increase progression free survival of patients with advanced stage AC, although there is currently no cure [27].

Understanding the underlying molecular pathways involved with cancer cell progression drives the development of novel therapeutics, and identifying and targeting molecules that drive neoplastic proliferation has become a major tool for combatting lung cancer. Specific therapies that inhibit carcinogenic pathways are now available for NSCLC patients with genetic aberrations such as epidermal growth factor receptor (EGFR) mutations, BRAF mutations and anaplastic lymphoma kinase (ALK) fusion translocations [18,25,28]. The EGFR gene encodes a receptor tyrosine kinase and mutations of this gene are commonly observed in lung AC. EGFR mutations are reported in approximately $50 \%$ of Asian AC patients, and $20 \%$ of Western patients with AC [29]. Patients that are EGFR mutation positive have exhibited sensitivity to TKIs, such as Gefitinib, which has been implemented in treatment regimens since 2003 [30]. Another molecular targeted therapy, Crizotinib, is recommended as first-line treatment for patients with ALK gene rearrangements, which are present in approximately $3-6 \%$ of AC patients, particularly in non-smokers [18,31-33]. The BRAF gene encodes a protein in the serine threonine kinase family, and mutations are present in $1-3 \%$ of NSCLC patients $[34,35]$. Two therapies that target proteins in the serine threonine kinase family, dabrafinib and trametinib, have been approved for patients with the BRAF mutation, and have been shown to slow tumour growth [36,37].

As EGFR, ALK and BRAF mutations are targetable aberrations observed in AC, and as TKIs are associated with increased progression free survival and a lower toxicity than chemotherapeutic agents, molecular testing for these mutations on bronchoscopy cytology samples has now become a major part of the diagnostic work up of NSCLC, and is considered imperative for formulating treatment strategies [25,38-40].

Chemotherapy remains the cornerstone treatment strategy for most patients with SCC, as targeting the potentially actionable mutations currently shows little therapeutic benefit for patients with SCC. Although, the recent approval of the monoclonal antibody, Necitumumab, as first-line therapy in metastatic SCC has been shown to improve overall survival of patients with EGFR mutations [41].

The use of immunotherapeutics for patients with SCC is increasing. With the recent approval of three immune checkpoint inhibitors, nivolumab, atezolizumab and pembrolizumab, for SCC patients with PDL1 positive tumours, patients receiving immunotherapy demonstrate prolonged overall survival, increased objective response rate and progression free survival, compared with systemic chemotherapy [20-24,42-44]. Testing for PD-L1, which is an immune molecule capable of inhibiting an anticancer immune response, is now part of the routine diagnostic algorithm of SCC [45-48], and expression is measured by the tumour proportion score. Patients with a proportion score greater than $50 \%$ may avail of first-line treatment with immunotherapy.

The increasing preference for personalised therapeutics for the treatment of NSCLC, is not only due to the negative side effects imparted on patients by non-selective chemotherapy, but also the increased progression free survival exhibited by patients in receipt of targeted therapies compared to chemotherapy [49,50]. Research for novel therapeutic markers is ongoing and includes studies investigating targetable molecules that drive carcinogenic progression such as FGFR, VEGFR-2, DDR2, P13 Kinase and PDGF, as well as novel immunotherapies [48,51]. As more targets and subsequent therapies are discovered, retaining adequate sample during the diagnostic work up of NSCLC for molecular testing will be imperative for future treatment planning.

\subsection{Current methods for differential diagnosis of NSCLC subtypes}

With the introduction of targeted therapies and immunotherapies, distinction between NSCLC and small cell lung cancer (SCLC) although paramount, is no longer adequate and further sub-classification of NSCLC is required. Although the most common symptoms associated with lung cancer are cough, dyspnea, chest pain and haemoptysis, lung cancer often presents with no symptoms until it has reached advanced stages, resulting in the majority of patients presenting with distant metastasis of the disease at diagnosis [15,52]. The following paragraphs detail the current methods used to acquire lung samples for analysis and the diagnostic tests used.

\subsection{Bronchoscopy}

Bronchoscopy is employed as an investigatory technique subsequent to the detection of an abnormality within the lung using CT scanning or X-rays [53]. Flexible bronchoscopy was first developed during the 1960 s and remains one of the principal diagnostic methods in pulmonology. In the case of suspected lung cancers, the main focus of 
bronchoscopy is to attain a sample of the suspicious lesion for diagnostic analysis [54]. At present, morphological evaluation of small specimens is the principal method used to differentially diagnose lung cancers. Accordingly, flexible bronchoscopy has evolved with the addition of adjunct applications including navigational bronchoscopy, endobronchial ultrasound, and bronchial thermoplasty, making it an effective method for obtaining minimally invasive cytology samples [55].

\subsection{Tumour classification utilising cytology specimens}

Small biopsy and cytology samples are the primary methods used for NSCLC diagnosis as these inflict less discomfort on the patients and still allow accurate identification of malignancy. Abrasive and exfoliative methods such as bronchial washing, brushing and bronchioalveolar lavage (BAL) are frequently utilised to attain samples from bronchoscopy for cytological analysis [56-58]. According to international multidisciplinary classification systems approximately $70 \%$ of lung cancer histological subtypes are diagnosed by assessing the predominant cytological pattern of small biopsies and cytological specimens, making cytological analysis a commonly implemented diagnostic method for NSCLC [59-61]. When a tumour does not show standard morphologic criteria for SCC or AC, immunohistochemical markers are used for further classification. Current guidelines suggest a vigilant use of immunohistochemstry (IHC) for diagnosis as limited cell sample remains for molecular testing for therapeutics, such as Fluorescent in situ hybridisation (FISH) and molecular sequencing [60].

\subsection{Immunohistochemistry}

IHC is concerned with the identification and distribution of cellular components through pinpointing specific antigens [62]. The application of IHC can be used to identify specific cell types by labelling tissue specific biomarkers. The method is based on antigen-antibody interactions, where the location of antibody binding is visualised by direct or secondary antibody labelling methods [63]. This is an effective technique used to discriminate between the different subtypes of NSCLC, and double IHC staining has been shown to be effective in the detection of AC [64].

A systematic review by Desai et al. [28] analysed data published between 2000 and 2012 and identified IHC as the most commonly used molecular testing technique for identifying biomarkers for the differential diagnosis of SCC and AC. The most frequently used biomarkers for this distinction are thyroid transcription factor 1 (TTF-1), EGFR, and the tumour suppressor gene p63 [28,48,49]. TTF- 1 modulates genes responsible for pulmonary morphogenesis and differentiation, and has exhibited elevated immunoreactivity in ACs $[65,66]$. The genomic profile of AC has also displayed an association with EGFR mutations [67], therefore the high prevalence of EGFR mutations in AC, alongside the recent development of molecular targeted therapies, makes it an effective marker for diagnosis as well as treatment strategy [68]. In contrast, p63 has been noted to display significantly higher positivity in SCCs than in ACs, making it a useful diagnostic indicator for SCC [65].

While IHC may be required to aid diagnosis in some cases, the technique is becoming increasingly applied in the realm of therapy prediction. It is not only imperative for the detection of treatment sensitive tumours, but also for the identification of those patients who may suffer ill effects where specific agents may be contraindicated. Despite the efficacy of IHC for the differential diagnosis of NSCLC subtypes, this diagnostic technique has multiple limiting factors. Although dual staining methods are now applicable with IHC, an additional slide is still required, significantly reducing the scant cellular material available for subsequent molecular testing. IHC also relies on the use of large molecules such as antibodies to label molecular structures, which interfere with further investigation of intrinsic molecular properties [69,70].

\subsection{Fluorescent in situ Hybridisation hybridisation}

FISH is an effective molecular testing technique for identifying fusion genes and has been approved by the FDA as the gold standard method for the detection of ALK rearrangements in NSCLC [71,72]. As IHC does not directly detect the ALK fusion gene, not all fusion positive tumours are positive using IHC [73,74]. FISH however has the ability to directly detect ALK fusions and also has an overall sensitivity and specificity higher than IHC for the identification of ALK gene aberrations in NSCLC [73,75]. Despite being a powerful technique needed for ALK testing and identifying patients that may respond to molecular targeted therapy, FISH requires the limited residual sample left over from diagnosis.

\subsection{Current research on genomic profiling}

In the era of personalised therapies and as new molecular markers are discovered, molecular testing is becoming part of the routine diagnostic workup of NSCLC. Current research is investigating potential molecular markers which may act as therapeutic targets or predictors of response to therapy [76-78].

Genomic and molecular profiles of AC and SCC are being developed using techniques applicable on archival cancer samples such as mass spectrometry and next generation sequencing. These techniques have been used to investigate the genomic profile of AC and have identified some high frequency mutations associated with the AC subtype, such as EGFR, MET, FGFR and HER2 [38,76-78].

Genomic hybridisation has been used in a number of studies to explore the gene-phenotype relationship of NSCLC subtypes, and research using this technique has identified entire chromosomal regions and individual genes which are applicable for the discrimination of AC and SCC. Using residual bronchial brush samples, Su et al. [79] identified 19 genes that are applicable for the discrimination of SCC and AC, many of the genes associated with epidermis development and cell adhesion and may present as potential therapeutic markers. Lockwood et al. [80] identified an entire chromosomal region (8p12) which may be valuable for profiling NSCLC subtypes. A gene within this region, BRF2, was identified as a SCC specific genetic amplification, and indicates that this gene is a promising marker for SCC. As BRF2 encodes a protein involved in transcription initiation and facilitates in transcribing proteins required for cell growth, it may present as a novel target for future therapies.

With the expanding demand for genomic profiling there is an increased demand on limited cell sample. The optimisation of diagnostic processes is therefore paramount to retain cellular material for subsequent molecular analysis such as genomic profiling.

\subsection{Limitations of current diagnostic methods}

Although IHC is a highly accurate technique for discriminating SCC and $\mathrm{AC}$, this diagnostic technique significantly reduces the amount of sample available for subsequent molecular testing, and as previously discussed, molecular profiling of the tumour is paramount in order to ensure efficacy of treatment. The demand for limited samples is ever increasing, this drives the need for an alternative diagnostic method which can be applied to small tissue and cytology samples without compromising subsequent applications $[69,70]$. In response to the need for new diagnostic methods, the investigation of alternative methods such as vibrational spectroscopy has been growing in recent years. The following section will discuss vibrational spectroscopy methods, such as Fourier Transform Infrared (FTIR) spectroscopy and Raman spectroscopy, as alternative techniques for the diagnosis of lung cancer.

\section{Vibrational spectroscopy}

Vibrational spectroscopy uses electromagnetic radiation to probe 


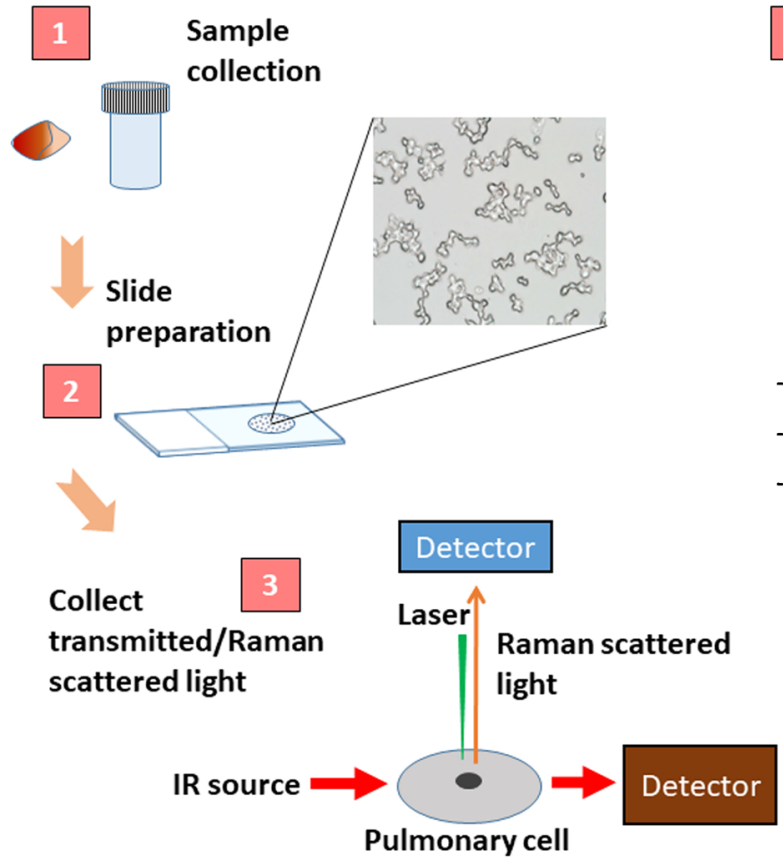

vibrations within molecules, and allows analysis of such molecular vibrations [81]. Molecular vibrational energies are routinely investigated using Fourier transform infrared (FTIR) spectroscopy and Raman spectroscopy. Fig. 1 demonstrates the process involved in applying vibrational spectroscopy to biological specimens for cancer detection.

\subsection{FTIR spectroscopy for lung cancer diagnosis}

Fourier transform infrared spectroscopy (FTIR) spectroscopy is a label free vibrational spectroscopic technique, which necessitates minimal sample pre-treatment [81-83]. When applied to biological tissue, the FTIR spectrum reveals comprehensive detail about the molecular content of the tissue. Intracellular changes induced by cancer states may be detected as variations from the spectral profile of normal tissue. The use of FTIR spectroscopy for lung cancer diagnosis has been investigated for over 20 years, with previous reports examining the applicability of FTIR spectroscopy for lung cancer investigation using in vitro models and ex vivo samples $[84,85]$. The in vitro studies included exploring the ability of FTIR spectroscopy to discriminate normal and cancer cells, and assessing lung cancer cells response to therapy [86,87]. Lee et al. [86] differentiated normal and lung cancer cell lines and reported differences in nucleic acid and phospholipid bands in the malignant lines. Sulé-Suso et al. [87] demonstrated the ability of FTIR spectroscopy to detect therapeutic response in lung cancer cell lines after the addition of a chemotherapeutic agent. The FTIR spectra indicated an increase in phosphate groups in the cells after the addition of the chemotherapeutic agent. The spectral changes detected were correlated with cell survival, showing that FTIR spectroscopy may potentially identify treatment sensitive cells. The study also demonstrates the suitability of FTIR spectroscopy for single cell analysis.

Although cell line studies provide proof of concept, stronger evidence to support the feasibility of using FTIR spectroscopy for lung cancer diagnosis are provided by applying the technique to surgically resected samples. A pilot study conducted by Xiaoliang et al. [88] used surgically resected tissue from 60 patients and applied a variation of FTIR spectroscopy, attenuated total reflection (ATR) FTIR spectroscopy to collect spectra from malignant and non-malignant tissues. The study showed the ability to detect the presence of lung malignancy with a
Multivariate analysis



Data processing
Fig. 1. Flow diagram of the process involved in applying vibrational spectroscopy to bronchoscopy obtained specimens for cancer detection. After obtaining the cytology/biopsy sample the biological material is stored in a preservative. The tissue section or cellular material is then fixed to a substrate such as a glass slide and left unstained for spectroscopic analysis. Using a laser or an infrared source, spectra are obtained by collecting the Raman scattered light or transmitted light. The spectral data are then pre-processed to minimise noise and spectral contaminations. Diagnostic features are then extracted from the data with multivariate analytical techniques. sensitivity, specificity and accuracy of $96.7 \%$. In addition to allowing the classification of neoplastic changes with high diagnostic accuracy, analysis of FTIR spectra reveals the molecular differences between malignant and non-malignant lung tissue. Yano et al. [84,89] described the increase in glycogen content of NSCLC tissue sections compared to non-cancerous tissue sections.

Akalin et al. [90] used a machine based learning approach to show that spectral profiles can distinguish between normal and cancerous tissues with high accuracy. They also reported the ability of IR spectroscopy to accurately classify SCLC, as well as the NSCLC subtypes AC and SCC. The authors indicated that this method may potentially be used to identify clinically significant subtypes of AC, although training and test data sets of adequate size were not available for their study. Further classification of AC into prognostically different groups was achieved by Grosserueschkamp et al. [91]. Using representative spectra for each subtype a supervised classifier was constructed. The first and second level random forests separated between normal tissue, diseased tissue and lung cancer subtypes. The third level random forest enabled further classification of AC into prognostically relevant subtypes, the favourable non-mucinous lipidic subtype, less favourable papillary and acinar subtypes, and the poor solid and micropapillary subtypes. A discrimination accuracy of $97 \%$ for cancer subtypes and $95 \%$ for AC subtypes was reported [91].

As cytological samples are the least invasive samples to attain for the diagnosis of NSCLC, several studies have assessed the ability of FTIR spectroscopy to characterise lung cancer using pulmonary cytological samples. Ghosal et al. [92,93] have demonstrated the feasibility of applying FTIR spectroscopy to sputum samples to detect lung cancer. Using two wavenumbers $\left(1031.7,1409.7 \mathrm{~cm}^{-1}\right)$ to develop a predictive model, lung cancer cells were identified with a sensitivity and specificity over 91\%. Lewis et al. [94] generated FTIR spectra from sputum cell pellets, and identified an increase in glycogen in the lung cancer cells. This finding is in accordance with multiple studies and signifies that elevated glycogen content may be a useful diagnostic biomarker for lung cancer using FTIR spectroscopy $[84,85,89]$. These studies demonstrate that applying this powerful diagnostic technique to cytological specimens for the detection of lung cancer in a clinical setting is a realistic prospect. In addition, FTIR spectroscopic analysis of sputum 
samples may be a cost effective and fast tool for lung cancer screening due to the non-invasive procedure of obtaining sputum samples and high throughput FTIR technology. In order for the application of FTIR spectroscopy to progress from a research setting to preclinical or clinical trials, an interdisciplinary approach is required to validate the performance of spectral biomarkers with a sufficient number of patients. The complexity and current availability of these validated models is a significant limitation for the application FTIR for lung cancer diagnosis.

\subsection{Raman spectroscopy for lung cancer diagnosis}

Raman spectroscopy has been discussed as a promising tool for cancer diagnostics for over 20 years [95]. Multiple reviews have illustrated how this spectroscopic technique has demonstrated favourable results for the identification of cancerous tissue and has the potential to improve cancer diagnostics in a variety of cancers including brain, breast, skin, lung and gastrointestinal cancer [96-99]. As with FTIR spectroscopy, Raman spectroscopy is a form of non-invasive, label free vibrational spectroscopy, however Raman spectroscopy relies on the detection of inelastically scattered light [82,100,101]. The Raman spectrum is a plot of the intensity of the scattered light versus the change in energy given in wavenumbers $\left(\mathrm{cm}^{-1}\right)$, and represents a detailed biochemical fingerprint of the cellular components, as shown in Fig. 2. As Raman spectroscopy provides comprehensive details about the composition of tissues, biochemical changes in cancerous tissue may be detected in the Raman spectra. Combining Raman spectroscopy with multivariate analysis can enable a highly accurate classification of tissue types and malignancy. In recent years, many studies have shown the efficacy of Raman spectroscopy for detecting lung cancer in vitro, $e x$ vivo and intraoperatively. Work by Jess et al. [102] showed the potential of Raman spectroscopy for grading of lung neoplasia in cellular samples. The cell lines utilised in the study were representative of three groups, normal cells (primary normal bronchial epithelial cells HBEpCs), cells with extended lifespan (HBEpCs retrovirally transduced with either human papillomavirus (HPV) type 16 E7 or CDK4), and immortalised or malignantly transformed cells (BEP2D and AsbTB2A). BEP2D is a human bronchial epithelial cell line expressing HPV18, and AsbTB2A is a transformed cell line derived from BEP2D following exposure to asbestos. A multivariate classification model based on linear discriminant analysis classified the cell types with accuracies ranging from $58 \%-77 \%$. Normal cells were discriminated from all abnormal cell types with a sensitivity of $91 \%$ and specificity of $75 \%$. The Raman spectra indicated that normal cells, cells with extended lifespan, and immortalised and transformed cells, could be characterised by their DNA, protein, amide and lipid content, suggesting that Raman spectroscopy may identify stage of lung cancer development [102].

The efficacy of Raman spectroscopy for the in vitro discrimination of normal and cancerous cells was also investigated by Oshima et al. [103]. Five lung cell lines from different histological origins were analysed (MRC-5 from normal, RERF-LC-MS from AC, EBC-1 from SCC, Lu-65 from large cell undifferentiated, and RERF-LC-MA from small cell carcinoma). The study showed that step-wise linear discrimination analysis of the Raman spectra allowed the label-free detection of each histological cell type with an accuracy of $100 \%$, validating the effectiveness of Raman spectroscopy for cancer cell diagnosis.

In addition to the assessment of in vitro models, the applicability of using Raman spectroscopy for the assessment of surgically resected samples has been explored. Using a $1064 \mathrm{~nm}$ laser to eliminate background fluorescence, Kaminaka et al. [104] investigated the molecular differences between normal and malignant lung tissue. Spectra with a high signal to noise ratio were obtained and distinct Raman bands at 1448 and $1666 \mathrm{~cm}^{-1}$ differentiated the normal and cancer spectral profiles. This demonstrated that an increase in collagen content in lung cancer tissue is detectable with Raman spectroscopy.

In 2012 Pavićević et al. [105] applied Raman spectroscopy to tissue samples from an array of different tumour types, which included lung SCC, and AC. Using PCA and a neural network algorithm, the SCC and AC subtypes were correctly classified with accuracies of $83.3 \%$ and $91.7 \%$ respectively. Normal and tumour tissue spectra were also discriminated with an overall sensitivity of $95 \%$. Huang et al. [106] applied Raman spectroscopy to biopsy samples to differentiate normal, AC, and SCC tissue and discovered significant differences between the spectra of normal and cancerous tissue. The Raman spectra indicated that the malignant tissue was characterised by an increase of nucleic acids, tryptophan and phenylalanine, in comparison to the normal tissue, while the AC and SCC subtypes were discriminated by a different ratio of peak intensities at $1455 \mathrm{~cm}^{-1}$ and $1655 \mathrm{~cm}^{-1}$, corresponding to a variation in lipid to protein ratio.

Gao et al. [107,108] applied another form of Raman spectroscopy, Coherent anti-Stokes Raman Scattering (CARS), to frozen lung tissue samples, differentiating normal and benign tumours, cancerous and non-cancerous tissues, and subsets of lung cancers. The authors developed a highly accurate classification system which delineated malignant tissue from normal tissue with classification accuracy over $91 \%$, and successfully differentiated small cell and NSCLC. An investigation by Magee et al. [109] using surgically resected samples achieved a sensitivity of $84 \%$ and a specificity of $61 \%$ for the discrimination of normal and cancer tissue, reporting that tumour tissue could be characterised by an increase in DNA and a decreased level of porphyrin in comparison to the normal tissue. In addition to showing the effectiveness of Raman spectroscopy to detect cancerous tissue, this study was

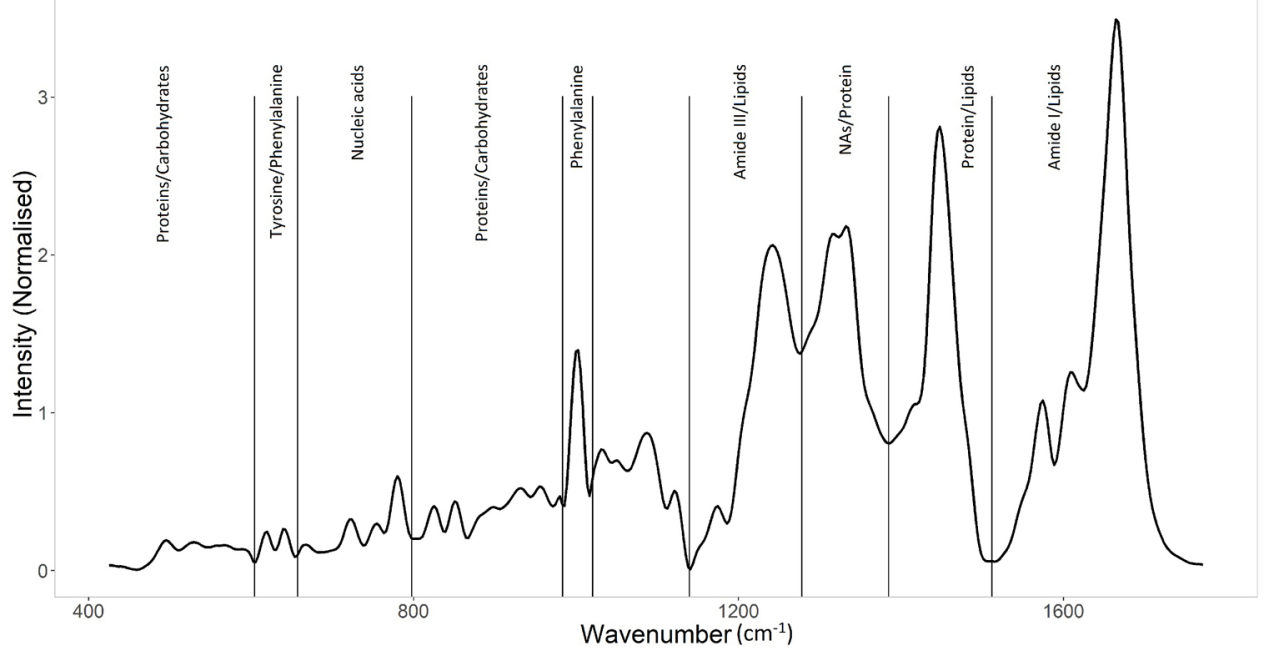

Fig. 2. Depiction of a Raman spectrum showing the different spectral regions and the corresponding biomolecules associated with each region. The spectrum which represents a bronchial epithelial cell nucleus was baseline corrected and the non-negatively constrained least squares method was used to remove spectral contaminants from the substrate. 
the first to demonstrate a prognostic ability of Raman spectroscopy to predict cancer recurrence in patients with a sensitivity and specificity of $73 \%$ and $74 \%$ respectively [109].

The CARS variant of Raman spectroscopy utilises multiple pulsed laser beams that interact with the sample through a wave mixing process and produces a signal that is much higher than the spontaneous Raman signal. With no interference from fluorescence, it has been shown to be a suitable method for the differential diagnosis of NSCLC, while preserving tissue specimens for follow up diagnostic tests [110-112]. Xu et al. [111] applied CARS as part of a multimodal imaging technique to unfixed, unstained lung tissue to effectively differentiate normal lung tissue, cancer tissue, and desmoplastic tissue. In another study by Gao et al. [112], a label free diagnostic system was developed by applying a 3D imaging strategy in conjunction with CARS to differentiate NSCLC subtypes. Human AC and SCC cell lines were grown in mouse models, and the tumours were excised after 2 weeks of growth. By acquiring individual 2D images of the same field of view from different imaging depths, the authors created a 3D data structure of the tissue. The system enabled a more accurate analysis of whole cells and nuclear size, overcoming the limitations of 2D sections. The NSCLC subtypes were differentiated with an accuracy of 97\%, proving the ability of vibrational spectroscopy to improve the current diagnostic algorithm with minimal sample consumption and without hindering additional molecular testing.

Surface enhanced Raman spectroscopy (SERS) has also been applied to biological samples including saliva and cell derived exosomes to characterise biomolecular differences between normal lung and lung cancer [113,114]. Zhang et al. [115] examined the prospects of implementing SERS in lung cancer diagnostics by applying SERS technology to lung tissue sections and developing a PC-LDA classifier to analyse the data. The study identified characteristic changes in the cancer spectra associated with increased DNA, carotenoids, lipids and proteins. After performing PC-LDA, a ROC curve was constructed to evaluate the performance of the developed classifier, and a diagnostic sensitivity of $95.7 \%$ and specificity of $95.7 \%$ was achieved for the discrimination of normal and malignant lung tissue.

The use of Raman spectroscopy to improve the in vivo diagnosis of lung cancer has also been investigated and presents as an exciting clinical application for the real-time diagnosis of NSCLC, which may prevent the need for surgical biopsy procedure. In 2008 Short et al. [116] designed an endoscopic Raman probe and acquired the first in vivo lung Raman spectra. With 1-2 second integration times and filters to reduce noise and fluorescence, quality Raman spectra were acquired in the high frequency spectral range from normal, dysplastic, and tumour sites. Analysis of the spectral profiles showed large variations between the SCC and normal tissue, although due to the low number of patients involved in the study the authors could not rule out interpatient variability as a potential cause. The following year a pilot study by Magee et al. [117] then provided proof of concept for the suitability of applying Raman spectroscopy for the in vivo diagnosis of lung cancer. Using a biomedical filtered fibre optic probe and a method to reduce background fluorescence, clear Raman spectra were acquired from ex vivo normal and malignant lung tissue. Spectral variation analysis identified increased peak intensities for amide I $\left(1655 \mathrm{~cm}^{-1}\right)$, amide III $\left(1260 \mathrm{~cm}^{-1}\right)$, and phenylalanine $\left(1002 \mathrm{~cm}^{-1}\right)$ in the tumour spectra. The normal and tumour spectra were also classified with $100 \%$ accuracy using PCA leave one out cross validation. In 2016, a single centre clinical investigation with 80 patients explored the adjunct application of Raman spectroscopy with bronchoscopic methods for the in vivo detection of lung cancer [118]. Real time point laser Raman spectroscopy ( $1 \mathrm{~s}$ per spectrum) was performed on 280 sites from non-malignant and malignant lung lesions. Multivariate analysis of the spectra differentiated the normal, benign and malignant tissue with a sensitivity of $90 \%$ and specificity of $65 \%$.

Raman technology also has the potential to help clinicians decide which lesions are suitable for biopsy, as the adjunct use of in vivo
Raman spectroscopy with bronchoscopy methods has been shown to detect preneoplastic lesions with sensitivity and specificity above $90 \%$ [119]. These studies show that Raman spectroscopy is a highly sensitive method for the in vivo diagnosis of lung cancer, and now with the ability to detect tumours in the peripheral lung with novel miniature Raman probe technology [120], and the capacity to produce clear spectra from weak Raman signals, further multicentre clinical trials are warranted.

In addition to in vivo and ex vivo studies, others have explored the feasibility of applying Raman spectroscopy combined with data mining methods to body fluid samples for lung cancer diagnosis. These are promising, cost effective methods and would allow simple and reliable screening to detect early stage malignancy. Analysing the serum of patients with NSCLC, Wang et al. [121] were able to obtain distinct Raman spectral profiles for stage I, stage II, and advanced stage NSCLC. Comparative analysis of the mean spectral profiles for each stage of NSCLC revealed multiple peaks involved in the carcinogenic progression of NSCLC. Cancer progression corresponded with a decrease in all of the analysed peak intensities. The authors noted that protein and phospholipid content was significantly reduced in the serum samples of NSCLC patients, evident by a decreased peak intensity at $1658 \mathrm{~cm}^{-1}$. With PCA and discriminant analysis, spectra taken from the sera of healthy people and patients with stage I- IV NSCLC were differentiated with an overall accuracy of $92 \%$. Other studies have shown that Raman spectroscopy also has the potential to characterise lung cancer and detect malignancy with high diagnostic sensitivities and specificities with non-invasive samples such as saliva and urine [114,122,123]. Applying Raman spectroscopy to these minimally invasive specimen types may be an effective tool for NSCLC screening and staging without the need for bronchoscopy. The translation of these technologies into a clinical setting now requires successful randomised clinical trials before they are accepted.

As discussed in this review, applying Raman spectroscopy to tissue sections has shown the ability to discriminate between non-malignant and malignant lung tissue, and between NSCLC subtypes. Raman technology has also been successfully applied to single cells, effectively identifying malignancy. However, based on a comprehensive review of the literature it appears no studies have investigated the use of Raman spectroscopy on bronchoscopy cytology samples, which would align with the current sampling techniques for lung cancer. In light of the research to date, applying this technique to cytology samples may present as a minimally invasive method for identifying and discriminating NSCLC subtypes and treatment sensitive tumours. This method may be used to provide an accurate diagnosis and retain sufficient sample for ancillary molecular tests, maximising the use of limited samples.

\subsection{Summary and future perspectives}

Small tissue and cytology samples are often the only specimens available for the diagnosis and molecular analysis of NSCLC. Current diagnostic methods for NSCLC consume much of the available sample, and with an increasing demand for the sample for ancillary molecular tests, an alternative accurate diagnostic method is desirable. As vibrational spectroscopic techniques are label free, highly sensitive and allow the rapid detection of intracellular biochemical information, they addresses the limitations of current diagnostic methods and are a potential option for the differential diagnosis of NSCLC. As vibrational spectroscopy is non-destructive, the unstained slides can be used for subsequent analysis.

Numerous studies have demonstrated the ability of vibrational spectroscopic techniques to accurately detect and discriminate lung cancer subtypes using tissue and cell samples. As the process of obtaining cell specimens is minimally invasive, future research may investigate the viability of using vibrational spectroscopic methods on bronchoscopy cytology samples. A previous study has already shown the ability of FTIR spectroscopy to characterise lung cancer cells using 
cytological samples, and although Raman spectroscopy has been investigated on lung carcinoma samples in vitro, ex vivo, and in vivo, to our knowledge it has never been used on bronchoscopy attained cytology samples [94,103,106,108,119].

As probe based Raman spectroscopy is developing and is a promising technique for the in vivo diagnosis of cancer, development in the application of Raman spectroscopy for the in vivo diagnosis of NSCLC may present with many promising advantages for clinical setting $[118,124,125]$. It can be used at a lower cost than other imaging techniques including magnetic resonance imaging (MRI) and ultrasound, in addition to giving real time information on biochemical composition in high resolution with no stains or labels [98].

\section{Conclusion}

As the identification of NSCLC subtype is pertinent for the development of treatment regimens, an enhanced label-free, rapid, and even automated diagnostic technique would be largely beneficial. Integrating vibrational spectroscopic methods into the diagnostic algorithm for lung cancer offers the ability to provide an accurate diagnosis and discover new molecular markers for the discrimination of NSCLC subtypes. Vibrational spectroscopic methods may be useful for the non-destructive analysis of small unstained bronchoscopy attained samples, without compromising subsequent ancillary molecular tests. These techniques have the potential to reduce the need for surgical biopsies, and may be economically advantageous by saving medical resources.

Declaration of Competing Interest

The authors declare no conflict of interest.

\section{Acknowledgments}

The authors acknowledge funding from the Fiosraigh Scholarship Dean of Graduate Research School Award.

\section{References}

[1] J. Ferlay, I.I. Soerjomataram, R. Dikshit, S. Eser, C. Mathers, M. Rebelo, et al., Cancer incidence and mortality worldwide: sources, methods and major patterns in GLOBOCAN, Int. J. Cancer 136 (5) (2012) E359-E386 [Internet]. 2014 Sep 13 [cited 2014 Sep 25]; Available from: http://onlinelibrary.wiley.com/doi/10. 1002/ijc.29210/full.

[2] F. Bray, J. Ferlay, I. Soerjomataram, R.L. Siegel, L.A. Torre, A. Jemal, Global cancer statistics 2018: GLOBOCAN estimates of incidence and mortality worldwide for 36 cancers in 185 countries, CA Cancer J. Clin. U. S. 68 (November (6)) (2018) 394-424.

[3] C.I. Henschke, Early lung cancer action project, Cancer 89(S11 Wiley Subscription Services, Inc., A Wiley Company, 2000, pp. 2474-2482 Dec 1 [cited 2016 Jan 15]; Available from: http://onlinelibrary.wiley.com/doi/10.1002/10970142(20001201)89:11 +\%3C2474::AID-CNCR26\%3E3.0.CO;2-2/full.

[4] I. Guessous, J. Cornuz, F. Paccaud, Lung cancer screening: current situation and perspective, Swiss Med. Wkly. Switzerland 137 (June (21-22)) (2007) 304-311.

[5] American Cancer Society, Non-small Cell Lung Cancer Survival Rates by Stage [Internet], [cited 2015 Oct 15]. Available from: (2015) http://www.cancer.org/ cancer/lungcancer-non-smallcell/detailedguide/non-small-cell-lung-cancersurvival-rates.

[6] World Cancer Research Fund International, Lung Cancer Statistics, [cited 2015 Oct 10]. Available from: (2015) http://www.wcrf.org/int/cancer-facts-figures/dataspecific-cancers/lung-cancer-statistics.

[7] Research WCRFI for C. Food, Nutrition, Physical Activity, and the Prevention of Cancer: A Global Perspective, Washington, DC (2007).

[8] A.R. Vieira, L. Abar, S. Vingeliene, D.S.M. Chan, D. Aune, D. Navarro-Rosenblatt, et al., Fruits, vegetables and lung cancer risk: a systematic review and meta-analysis, Ann. Oncol. (September) (2015) Available from: http://annonc. oxfordjournals.org/content/early/2015/10/05/annonc.mdv381.abstract.

[9] K.A. Houston, S.J. Henley, J. Li, M.C. White, T.B. Richards, Patterns in lung cancer incidence rates and trends by histologic type in the United States, 2004-2009, Lung Cancer 86 (1) (2014) 22-28 [cited 2016 Jan 14]; Available from: http:// www.sciencedirect.com/science/article/pii/S0169500214003237.

[10] R.N. Pillai, T.K. Owonikoko, Small cell lung Cancer: therapies and targets, Semin. Oncol. 41 (1) (2014) 133-142. Available from: http://www.ncbi.nlm.nih.gov/ pmc/articles/PMC4176613/.

[11] R. Govindan, N. Page, D. Morgensztern, W. Read, R. Tierney, A. Vlahiotis, et al., Changing epidemiology of small-cell lung Cancer in the United States over the last
30 years: analysis of the surveillance, epidemiologic, and end results database, $\mathrm{J}$ Clin. Oncol. Am. Soc. Clin. Oncol. 24 (October (28)) (2006) 4539-4544.

[12] A. Jemal, R. Siegel, E. Ward, Y. Hao, J. Xu, T. Murray, et al., Cancer statistics, 2008, CA Cancer J. Clin. 58 (January (2)) (2019) 71-96. Available from: http:// www.ncbi.nlm.nih.gov/pubmed/18287387 [cited 2016 Oct 7].

[13] C.M.T. Sagerup, M. Smastuen, T.B. Johannesen, A. Helland, O.T. Brustugun, Sexspecific trends in lung cancer incidence and survival: a population study of 40,118 cases, Thorax. Engl. 66 (April (4)) (2011) 301-307.

[14] C.-Q. Zhu, M. Pintilie, T. John, D. Strumpf, F.A. Shepherd, S.D. Der, et al., Understanding prognostic gene expression signatures in lung cancer, Clin. Lung Cancer 10 (September (5)) (2009) 331-340. Available from: http://www. sciencedirect.com/science/article/pii/S1525730411704387 [cited 2015 Nov 24].

[15] W. Tan, Non-Small Cell Lung Cancer (2015) Available from:http://emedicine. medscape.com/article/279960-overview\#a6 [cited 2016 Jan 14]..

[16] Cancer Research UK, More About Staging for Lung Cancer, (2014) Available from: http://www.cancerresearchuk.org/about-cancer/type/lung-cancer/treatment/ more-about-lung-cancer-staging [cited 2016 Jan 21].

[17] J. Vansteenkiste, L. Crinò, C. Dooms, J.Y. Douillard, C. Faivre-Finn, E. Lim, et al., 2nd ESMO Consensus Conference on Lung Cancer: early-stage non-small-cell lung cancer consensus on diagnosis, treatment and follow-up, Ann. Oncol. 25 (August (8)) (2014) 1462-1474. Available from: http://annonc.oxfordjournals.org/cgi/ content/long/mdu089v2 [cited 2016 Jan 17].

[18] G.A. Masters, S. Temin, C.G. Azzoli, G. Giaccone, S. Baker, J.R. Brahmer, et al., Systemic therapy for stage IV non-small-Cell lung Cancer: american society of clinical oncology clinical practice guideline update, J. Clin. Oncol. (2015) Available from:http://jco.ascopubs.org/content/early/2015/08/31/JCO.2015.62 1342.abstract\#.VlSf4wuiBeQ.mendeley [cited 2015 Sep 1];JCO.2015.62.1342-..

[19] Cancer Research UK, Types of Treatment for Lung Cancer, [cited 2016 Feb 11]. Available from: Cancer Research UK, 2014, http://www.cancerresearchuk.org/ about-cancer/type/lung-cancer/treatment/which-treatment-for-lung-cancer.

[20] J. Brahmer, K.L. Reckamp, P. Baas, L. Crinò, W.E.E. Eberhardt, E. Poddubskaya, et al., Nivolumab versus docetaxel in advanced squamous-cell non-Small-Cell lung Cancer, N. Engl. J. Med. J373 (July (2)) (2015) 123-135.

[21] L. Horn, D.R. Spigel, E.E. Vokes, E. Holgado, N. Ready, M. Steins, et al., Nivolumab versus docetaxel in previously treated patients with advanced non-small-Cell lung Cancer: two-Year outcomes from two randomized, open-label, phase III trials (CheckMate 017 and CheckMate 057), J. Clin. Oncol. U. S. 35 (December (35)) (2017) 3924-3933.

[22] D.P. Carbone, M. Reck, L. Paz-Ares, B. Creelan, L. Horn, M. Steins, et al., First-line nivolumab in stage IV or recurrent non-small-Cell lung Cancer, N. Engl. J. Med. U. S. 376 (June (25)) (2017) 2415-2426.

[23] E.B. Garon, N.A. Rizvi, R. Hui, N. Leighl, A.S. Balmanoukian, J.P. Eder, et al., Pembrolizumab for the treatment of non-small-cell lung cancer, N. Engl. J. Med. U. S. 372 (May (1)) (2015) 2018-2028.

[24] M. Reck, S. Popat, N. Reinmuth, D. De Ruysscher, K.M. Kerr, S. Peters, Metastatic non-small-cell lung cancer (NSCLC): ESMO Clinical Practice Guidelines for diagnosis, treatment and follow-up广, Ann. Oncol. 25 (August (suppl_3)) (2014) iii27-39.

[25] M.B. Carper, P.P. Claudio, Clinical potential of gene mutations in lung cancer, Clin. Transl. Med. 4 (December (1)) (2015) 33.

[26] C. Allemani, H.K. Weir, H. Carreira, R. Harewood, D. Spika, X.-S. Wang, et al., Global surveillance of cancer survival 1995-2009: analysis of individual data for $25,676,887$ patients from 279 population-based registries in 67 countries (CONCORD-2), Lancet 385 (November (9972)) (2017) 977-1010 Elsevier.

[27] H. Yan, Q. Li, W. Wang, H. Zhen, B. Cao, Systems assessment of intercalated combination of chemotherapy and EGFR TKIs versus chemotherapy or EGFR TKIs alone in advanced NSCLC patients, Sci. Rep. 20 (October (5)) (2015) 15355. Available from: https://doi.org/10.1038/srep15355 [Macmillan Publishers Limited].

[28] C. Desai, A. Mehta, D. Mishra, Usage patterns of biomarkers in non-small-cell lung cancer patients in India: findings from a systematic review and survey, Lung India 31 (3) (2014) 249-259. Available from: http://www.ncbi.nlm.nih.gov/pmc/ articles/PMC4129597/ [[Internet]. India: Medknow Publications \& Media Pvt Ltd].

[29] A. Midha, S. Dearden, R. McCormack, EGFR mutation incidence in non-small-cell lung cancer of adenocarcinoma histology: a systematic review and global map by ethnicity (mutMapII), Am. J. Cancer Res. 5 (August (9)) (2015) 2892-2911. Available from: http://www.ncbi.nlm.nih.gov/pmc/articles/PMC4633915/ [eCentury Publishing Corporation].

[30] Administration USF\& D, FDA Approves Targeted Therapy for First-line Treatment of Patients With a Type of Metastatic Lung Cancer, (2015).

[31] K. Takeuchi, Y.L. Choi, M. Soda, K. Inamura, Y. Togashi, S. Hatano, et al., Multiplex reverse transcription-PCR screening for EML4-ALK fusion transcripts, Clin Cancer Res. United States 14 (October (20)) (2008) 6618-6624.

[32] K. Takeuchi, Y.L. Choi, Y. Togashi, M. Soda, S. Hatano, K. Inamura, et al., KIF5B ALK, a novel fusion oncokinase identified by an immunohistochemistry-based diagnostic system for ALK-positive lung cancer, Clin Cancer Res. United States 15 (May (9)) (2009) 3143-3149.

[33] American Cancer Society, Targeted Therapies for Non-small Cell Lung Cancer, (2015) Available from: http://www.cancer.org/cancer/lungcancer-non-smallcell/ detailedguide/non-small-cell-lung-cancer-treating-targeted-therapies\# [cited 2016 Jan 18].

[34] D. Chen, L.-Q. Zhang, J.-F. Huang, K. Liu, Z.-R. Chuai, Z. Yang, et al., BRAF mutations in patients with non-small cell lung Cancer: a systematic review and metaanalysis. Souglakos J, editor, PLoS One 9 (June(6)) (2014) e101354 San Francisco, USA: Public Library of Science. 
[35] W. Pao, N. Girard, New driver mutations in non-small-cell lung cancer, Lancet Oncol. England 12 (February (2)) (2011) 175-180.

[36] A. Khunger, M. Khunger, V. Velcheti, Dabrafenib in combination with trametinib in the treatment of patients with BRAF V600-positive advanced or metastatic nonsmall cell lung cancer: clinical evidence and experience, Ther. Adv. Respir. Dis. Engl. 12 (2018) 1753466618767611.

[37] U.S Food \& Drug Administration, FDA Grants Regular Approval to Dabrafenib and Trametinib Combination for Metastatic NSCLC With BRAF V600E Mutation, [cited 2017 Jan 16]. Available from: (2015) http://www.fda.gov/NewsEvents/ Newsroom/PressAnnouncements/ucm454678.htm.

[38] T. Li, H.-J. Kung, P.C. Mack, D.R. Gandara, Genotyping and Genomic Profiling of Non-Small-Cell Lung Cancer: Implications for Current and Future Therapies, J. Clin. Oncol. Am. Soc. Clin. Oncol. 31 (March (8)) (2013) 1039-1049. Available from: http://www.ncbi.nlm.nih.gov/pmc/articles/PMC3589700/.

[39] J. Greenhalgh, K. Dwan, A. Boland, V. Bates, F. Vecchio, Y. Dundar, et al., First line treatment of advanced epidermal growth factor receptor (EGFR) mutation positive non-squamous non-small cell lung cancer, Cochrane Satabase Syst. Rev. Engl. (May (5)) (2016) CD010383.

[40] N.I. Lindeman, P.T. Cagle, M.B. Beasley, D.A. Chitale, S. Dacic, G. Giaccone, et al., Molecular testing guideline for selection of lung Cancer patients for EGFR and ALK tyrosine kinase inhibitors: guideline from the college of american pathologists, international association for the study of lung Cancer, and association for molecular patho, Arch. Pathol. Lab. Med. 137 (June (6)) (2013) 828-860. Available from: http://www.ncbi.nlm.nih.gov/pmc/articles/PMC4162344/.

[41] L. Fala, Portrazza (Necitumumab), an IgG1 monoclonal antibody, FDA approved for advanced squamous non-small-Cell lung Cancer. Am heal drug benefits, Engage Healthcare Communications, LLC 9 (March (Spec Feature)) (2016) 119-122. Available from: https://www.ncbi.nlm.nih.gov/pubmed/27668058.

[42] A. Rittmeyer, F. Barlesi, D. Waterkamp, K. Park, F. Ciardiello, J. von Pawel, et al., Atezolizumab versus docetaxel in patients with previously treated non-small-cell lung cancer (OAK): a phase 3, open-label, multicentre randomised controlled trial, Lancet (London, England) 389 (January (10066)) (2017) 255-265.

[43] S. Peters, S. Gettinger, M.L. Johnson, P.A. Janne, M.C. Garassino, D. Christoph, et al., Phase II trial of atezolizumab As first-line or subsequent therapy for patients with programmed death-ligand 1-Selected advanced non-small-Cell lung Cancer (BIRCH), J. Clin. Oncol. U. S. 35 (August (24)) (2017) 2781-2789.

[44] N. Seetharamu, I.R. Preeshagul, K.M. Sullivan, New PD-L1 inhibitors in non-small cell lung cancer - impact of atezolizumab, Lung Cancer (Auckl.) 8 (2017) 67-78.

[45] A.B. Schulze, L.H. Schmidt, PD-1 targeted Immunotherapy as first-line therapy for advanced non-small-cell lung cancer patients, J. Thorac. Dis. 9 (April (4)) (2017) E384-E386. AME Publishing Company.

[46] G.V. Scagliotti, P. Bironzo, J.F. Vansteenkiste, Addressing the unmet need in lung cancer: the potential of immuno-oncology, Cancer Treat. Rev. 41 (June (6)) (2015) 465-475. Available from: http://www.sciencedirect.com/science/article/pii/ S0305737215000705.

[47] J. Villadolid, A. Amin, Immune checkpoint inhibitors in clinical practice: update on management of immune-related toxicities, Transl. Lung Cancer Res. 4 (October (5)) (2015) 560-575. Available from: http://www.ncbi.nlm.nih.gov/pmc/ articles/PMC4630514/; AME Publishing Company.

[48] B.A. Derman, K.F. Mileham, P.D. Bonomi, M. Batus, M.J. Fidler, Treatment of advanced squamous cell carcinoma of the lung: a review, Transl. Lung Cancer Res. 4 (October (5)) (2015) 524-532. Available from: http://www.ncbi.nlm.nih.gov/ pmc/articles/PMC4630512/; AME Publishing Company.

[49] M.J. Boyer, Drug therapy of lung cancer, Aust. Prescr. 26 (5) (2003).

[50] R. Rosell, E. Carcereny, R. Gervais, A. Vergnenegre, B. Massuti, E. Felip, et al., Erlotinib versus standard chemotherapy as first-line treatment for European patients with advanced EGFR mutation-positive non-small-cell lung cancer (EURTAC): a multicentre, open-label, randomised phase 3 trial, Lancet Oncol. 13 (March (3)) (2012) 239-246. Available from: http://www.sciencedirect.com/ science/article/pii/S147020451170393X.

[51] M. Méndez, A. Custodio, M. Provencio, New molecular targeted therapies for advanced non-small-cell lung cancer, J. Thorac Dis. 3 (March (1)) (2011) 30-56 Pioneer Bioscience Publishing Company.

[52] P.M. Ellis, R. Vandermeer, Delays in the diagnosis of lung cancer, J Thorac Dis. 3 (September (3)) (2011) 183-188 Pioneer Bioscience Publishing Company.

[53] F.A. Almeida, Bronchoscopy and endobronchial ultrasound for diagnosis and staging of lung cancer, Cleve Clin. J. Med. U. S. 79 (May) (2012) Electro: eS11-6..

[54] B.T. Society, Quality standards for diagnostic flexible bronchoscopy in adults, $\mathrm{Br}$ Thorac Soc Rep. 6 (5) (2014) 1-40.

[55] H.Y. Lim, S.H. Puah, Ang LJPS, E.Q. Teo, S.Y. Lau, K.S. Goh, et al., Subconjunctival haemorrhage from bronchoscopy: a case report, Respir. Med. Case Rep. 3 (September (16)) (2015) 97-100 Elsevier Available from: http://www.ncbi.nlm. nih.gov/pmc/articles/PMC4681957/.

[56] A. Strimpakos, E. Politi, E. Kainis, D. Grapsa, S. Siolos, S. Tsagouli, et al., The clinical significance of cytology versus histology-based diagnosis in small cell lung cancer: a retrospective study, Lung Cancer 85 (August (2)) (2014) 186-190. Available from: http://www.sciencedirect.com/science/article/pii/ S016950021400186X.

[57] M. Melamed, Tumors of the lung: conventional cytology and aspiration biopsy, in: L. Koss, M. Melamed (Eds.), Koss' Diagnostic Cytology and Its Histopathologic Bases, 5th edition, Lippincott Williams \& Wilkins, Philadelphia, 2006, pp. 643-712.

[58] M.O. Idowu, C.N. Powers, Lung cancer cytology: potential pitfalls and mimics - a review, Int. J. Clin. Exp. Pathol. 3 (March (4)) (2010) 367-385 e-Century Publishing Corporation (Available from: http://www.ncbi.nlm.nih.gov/pmc/ articles/PMC2872744/ ).
[59] S. Gasparini, Histology versus cytology in the diagnosis of lung cancer: is it a real advantage? J. Bronchol. Interv Pulmonol. U. S. 17 (April (2)) (2010) 103-105.

[60] W.D. Travis, E. Brambilla, A.G. Nicholson, Y. Yatabe, J.H.M. Austin, M.B. Beasley, et al., The 2015 world health organization classification of, J. Thorac Oncol. Int. Association Study of Lung Cancer 10 (9) (2015) 1243-1260.

[61] J. Zugazagoitia, A.B. Enguita, J.A. Nuñez, L. Iglesias, S. Ponce, The new IASLC/ ATS/ERS lung adenocarcinoma classification from a clinical perspective: current concepts and future prospects, J. Thorac. Dis. 6 (October (Suppl 5)) (2014) S526-36Pioneer Bioscience Publishing Company.

[62] D. Cook, The Study of Tissues and Their Diseases. in: Cellular Pathology, second edi., Scion Publishing Ltd, Oxfordshire, 2006, pp. 1-8.

[63] D. Dabbs, Techniques of immunohistochemistry: principles, pitfalls and standardization, in: D. Dabbs (Ed.), Diagnostic Immunohistochemistry, 2nd editio, Elsevier, Philadelphia, 2006, pp. 1-42.

[64] N. Fatima, C. Cohen, D. Lawson, M.T. Siddiqui, TTF-1 and Napsin A double stain: a useful marker for diagnosing lung adenocarcinoma on fine-needle aspiration cell blocks, Cancer Cytopathol. U. S. 119 (April (2)) (2011) 127-133.

[65] B. Yaman, D. Nart, P.K. Ekren, G. Cok, A. Veral, Expression of p63, TTF-1 and Maspin in Non-Small Cell Lung Carcinoma and Their Effect on the Prognosis and Differential Diagnosis, Turk Patoloji. Derg. 31 (3) (2015) 163-174.

[66] V. Boggaram, Thyroid transcription factor-1 (TTF-1/Nkx2.1/TITF1) gene regulation in the lung, Clin. Sci. 116 (Januaru (1)) (2009) 27-35. Available from: http:// www.clinsci.org/content/116/1/27.abstract.

[67] M. Planck, K. Edlund, J. Botling, P. Micke, S. Isaksson, J. Staaf, Genomic and transcriptional alterations in lung adenocarcinoma in relation to EGFR and KRAS mutation Status, in: P. Tan (Ed.), PLoS One, 8 October (10 Public Library of Science, San Francisco, USA, 2013, p. e78614. Available from:http://www.ncbi. nlm.nih.gov/pmc/articles/PMC3812039/.

[68] L. Wang, Z. Zhang, L. Huang, W. Li, Q. Lu, M. Wen, et al., Evaluation of Raman spectroscopy for diagnosing EGFR mutation status in lung adenocarcinoma, Analyst 139 (2) (2014) 455-463, https://doi.org/10.1039/C3AN01381B Available from:

[69] D.L. Aisner, C.B. Marshall, Molecular pathology of non-small cell lung cancer: a practical guide, Am. J. Clin. Pathol. U. S. 138 (September (3)) (2012) 332-346.

[70] E. Folch, D.B. Costa, J. Wright, P.A. VanderLaan, Lung cancer diagnosis and staging in the minimally invasive age with increasing demands for tissue analysis, Transl. Lung Cancer Res 13 (August (4)) (2015) 392-403. Available from: http:// www.ncbi.nlm.nih.gov/pmc/articles/PMC4549479/.

[71] T. Plönes, W. Engel-Riedel, E. Stoelben, C. Limmroth, O. Schildgen, V. Schildgen, Molecular pathology and personalized medicine: the dawn of a new era in companion diagnostics-practical considerations about companion diagnostics for nonsmall-Cell-Lung-Cancer, J. Pers. Med. 6 (1) (2016) 3. Available from: http://www. mdpi.com/2075-4426/6/1/3/htm Multidisciplinary Digital Publishing Institute [cited 2016 Jan 26].

[72] Y.-C. Wu, I.-C. Chang, C.-L. Wang, T.-D. Chen, Y.-T. Chen, H.-P. Liu, et al., Comparison of IHC, FISH and RT-PCR methods for detection of ALK rearrangements in 312 non-small cell lung Cancer patients in Taiwan. Aziz SA, editor, PLoS One 8 (August (8)) (2013) e70839. Available from: http://www.ncbi.nlm.nih.gov/ pmc/articles/PMC3737393/; San Francisco, USA: Public Library of Science.

[73] Y. Murakami, T. Mitsudomi, Y. Yatabe, A screening method for the ALK fusion gene in NSCLC, Front. Oncol. 16 (March (2)) (2012) 24. Available from: http:// www.ncbi.nlm.nih.gov/pmc/articles/PMC3356052/; Frontiers Research Foundation

[74] M.P. Martelli, G. Sozzi, L. Hernandez, V. Pettirossi, A. Navarro, D. Conte, et al., EML4-ALK rearrangement in non-small cell lung Cancer and non-tumor lung tissues, Am. J. Pathol. 174 (2) (2009) 661-670.

[75] E. Conde, A. Suárez-Gauthier, A. Benito, P. Garrido, R. García-Campelo, M. Biscuola, et al., Accurate identification of ALK positive lung carcinoma patients: novel FDA-Cleared automated fluorescence in situ hybridization scanning system and ultrasensitive immunohistochemistry. Franco R, editor, PLoS One 9 (September (9)) (2014) e107200. Available from: http://www.ncbi.nlm.nih.gov/ pmc/articles/PMC4172507/ ; San Francisco, USA: Public Library of Science.

[76] J. Xie, X. Zhang, The impact of genomic profiling for novel Cancer therapy - recent progress in non-small cell lung Cancer, J. Genet. Genomics 43 (January (1)) (2016) 3-10. Available from: http://www.sciencedirect.com/science/article/pii/ S1673852715001575 [cited 2016 Feb 23]

[77] A.T. Shaw, Ou S-HI, Y.-J. Bang, D.R. Camidge, B.J. Solomon, R. Salgia, et al., Crizotinib in ROS1-Rearranged non-Small-Cell lung Cancer, N. Engl. J. Med. 371 (November (21)) (2014) 1963-1971. Available from: http://www.ncbi.nlm.nih. gov/pmc/articles/PMC4264527/.

[78] D.S.W. Tan, S. Camilleri-Broët, E.H. Tan, M. Alifano, W.-T. Lim, A. Bobbio, et al., Intertumor heterogeneity of non-small-cell lung carcinomas revealed by multiplexed mutation profiling and integrative genomics, Int. J. Cancer 135 (September (5)) (2014) 1092-1100. Available from: http://onlinelibrary.wiley.com/doi/10. 1002/ijc.28750/full [cited 2016 Feb 23].

[79] Y. Su, L. Pan, Identification of logic relationships between genes and subtypes of non-small cell lung cancer, PLoS One 9 (4) (2014) e94644. Available from: http:// www.pubmedcentral.nih.gov/articlerender.fcgi? artid $=3990524 \&$ tool $=$ pmcentrez\&rendertype $=$ abstract ; [cited 2016 Jan 20].

[80] W.W. Lockwood, R. Chari, B.P. Coe, K.L. Thu, C. Garnis, C.A. Malloff, et al., Integrative genomic analyses identify BRF2 as a novel lineage-specific oncogene in lung squamous cell carcinoma. Pao w, editor, PLoS Med. 7 (7) (2010) e1000315. Available from: http://www.ncbi.nlm.nih.gov/pmc/articles/PMC2910599/; San Francisco, USA: Public Library of Science.

[81] S. Zhang, Fundamental theory of light scattering, in: Ltd JW\& S (Ed.), Raman Spectroscopy and Its Application in Nanostructures, 1st editio, John Wiley \& Sons, 
Ltd, Chichester, 2012, pp. 19-45.

[82] B. Stuart, D.J. Ando (Ed.), Infrared Spectroscopy: Fundamentals and Applications, John Wiley \& Sons, Inc, 2004, pp. 1-244.

[83] U. Platt, R. Guzzi, L. Lanzerotti, D. Imboden, U. Platt (Eds.), Stutz J. Differential Optical Absorption Spectroscopy, 1st ed., Springer-Verlag Berlin Heidelbeerg, Berlin, 2008, pp. 175-285.

[84] K. Yano, S. Ohoshima, Y. Shimizu, T. Moriguchi, H. Katayama, Evaluation of glycogen level in human lung carcinoma tissues by an infrared spectroscopic method, Cancer Lett. Ireland 110 (1-2) (1996) 29-34.

[85] H.P. Wang, H.C. Wang, Y.J. Huang, Microscopic FTIR studies of lung cancer cells in pleural fluid, Sci Total Environ. Netherlands 204 (3) (1997) 283-287.

[86] S.Y. Lee, K.-A. Yoon, S.H. Jang, E.O. Ganbold, D. Uuriintuya, S.-M. Shin, et al., Infrared spectroscopy characterization of normal and lung cancer cells originated from epithelium, J. Vet. Sci. 10 (4) (2009) 299-304. Available from: http://www. ncbi.nlm.nih.gov/pmc/articles/PMC2807265/; The Korean Society of Veterinary Science.

[87] J. Sulé-Suso, D. Skingsley, G.D. Sockalingum, A. Kohler, G. Kegelaer, M. Manfait, et al., FT-IR microspectroscopy as a tool to assess lung cancer cells response to chemotherapy, Vib. Spectrosc. 38 (1-2) (2005) 179-184. Available from: http:// www.sciencedirect.com/science/article/pii/S092420310500038X [cited 2016 May 24].

[88] X. Sun, Y. Xu, J. Wu, Y. Zhang, K. Sun, Detection of lung cancer tissue by attenuated total reflection-Fourier transform infrared spectroscopy-a pilot study of 60 samples, J. Surg. Res. 179 (1) (2013) 33-38. Available from: http://www. sciencedirect.com/science/article/pii/S0022480412008050 [cited 2016 Mar 21].

[89] K. Yano, S. Ohoshima, Y. Gotou, K. Kumaido, T. Moriguchi, H. Katayama, Direct measurement of human lung cancerous and noncancerous tissues by fourier transform infrared microscopy: can an infrared microscope be used as a clinical tool? Anal. Biochem. 287 (2) (2000) 218-225. Available from: http://www. sciencedirect.com/science/article/pii/S0003269700948723 [cited 2016 May 23].

[90] A. Akalin, X. Mu, M.A. Kon, A. Ergin, S.H. Remiszewski, C.M. Thompson, et al., Classification of malignant and benign tumors of the lung by infrared spectral histopathology (SHP), Lab. Invest. 95 (4) (2015) 406-421. Available from: https://doi.org/10.1038/labinvest.2015.1 ; United States \& Canadian Academy of Pathology.

[91] F. Grosserueschkamp, A. Kallenbach-Thieltges, T. Behrens, T. Bruning, M. Altmayer, G. Stamatis, et al., Marker-free automated histopathological annotation of lung tumour subtypes by FTIR imaging, Analyst. England 140 (7) (2015) 2114-2120.

[92] R. Ghosal, K.E. Lewis, P. Kloer, S. Bayliss, L. Mur, P.D. Lewis, S38 Fourier transform infra-red (FTIR) spectroscopy on sputum from lung cancer patients, healthy controls and a high-risk cohort, Thorax 65 (Suppl 4) (2010) A19 LP-A20. Available from: http://thorax.bmj.com/content/65/Suppl 4/A19.2.abstract.

[93] R. Ghosal, K.E.L. Lewis, P. Kloer, R. Mehta, D. Parry, C. Llewllyn-Jones, et al., Using Fourier transform infrared (FTIR) spectroscopy to evaluate metabolic markers in sputum in patients with and without lung cancer, Lung Cancer 1 (60) (2008) S11. Available from: https://doi.org/10.1016/S0169-5002(08)70033-3 ; Elsevier.

[94] P.D. Lewis, K.E. Lewis, R. Ghosal, S. Bayliss, A.J. Lloyd, J. Wills, et al., Evaluation of FTIR Spectroscopy as a diagnostic tool for lung cancer using sputum, BMC Cancer 10 (2010) 640. Available from: http://www.ncbi.nlm.nih.gov/pmc/ articles/PMC3000851/; BioMed Central.

[95] A. Mahadevan-Jansen, R. Richards-Kortum, Raman spectroscopy for cancer detection: a review, 19th International Conference - IEEE/EMBS (1997) 2722-2728. Available from: http://kortum.rice.edu/uploadedFiles/Kortum/Publications/ 1997_Publications/RamanSpectroscopyforCancerDetectionA Review.pdf.

[96] S. Coda, P.D. Siersema, G.W.H. Stamp, A.V. Thillainayagam, Biophotonic endoscopy: a review of clinical research techniques for optical imaging and sensing of early gastrointestinal cancer, Endosc. Int. Open 3 (5) (2015) E380-E392. Available from: http://www.ncbi.nlm.nih.gov/pmc/articles/PMC4612244/ ; Stuttgart New York: (C) Georg Thieme Verlag KG.

[97] M.B. Fenn, P. Xanthopoulos, G. Pyrgiotakis, S.R. Grobmyer, P.M. Pardalos, L.L. Hench, Raman spectroscopy for clinical oncology, Adv Opt Technol. 2011 (2011) 1-20.

[98] K. Kong, C. Kendall, N. Stone, I. Notingher, Raman spectroscopy for medical diagnostics - from in-vitro biofluid assays to in-vivo cancer detection, Adv. Drug Deliv. Rev. 89 (2015) 121-134. Available from: http://www.sciencedirect.com/ science/article/pii/S0169409X15000447.

[99] H. Zeng, A. McWilliams, S. Lam, Optical spectroscopy and imaging for early lung cancer detection: a review, Photodiagnosis Photodyn Ther. Netherlands 1 (2) (2004) 111-122.

[100] G.S. Bumbrah, R.M. Sharma, Raman spectroscopy - basic principle, instrumentation and selected applications for the characterization of drugs of abuse, Egypt. J. Forensic Sci. 6 (3) (2016) 209-215.

[101] E. Smith, Dent G. Modern Raman Spectroscopy - a Practical Approach, John Wiley \& Sons, Ltd, Chichester, 2005, pp. 1-112.

[102] P.R.T. Jess, M. Mazilu, K. Dholakia, A.C. Riches, C.S. Herrington, Optical detection and grading of lung neoplasia by Raman microspectroscopy, Int. J. Cancer 124 (2) (2009) 376-380 [cited 2016 Feb 11] Available from: http://onlinelibrary.wiley. com/doi/10.1002/ijc.23953/full ; Wiley Subscription Services, Inc., A Wiley Company.
[103] Y. Oshima, H. Shinzawa, T. Takenaka, C. Furihata, H. Sato, Discrimination analysis of human lung cancer cells associated with histological type and malignancy using Raman spectroscopy, J. Biomed. Opt. 15 (1) (2010) 17008-17009, https:// doi.org/10.1117/1.3316296 Available from:

[104] S. Kaminaka, H. Yamazaki, T. Ito, E. Kohda, H. Hamaguchi, Near-infrared Raman spectroscopy of human lung tissues: possibility of molecular-level cancer diagnosis, J Raman Spectrosc. John Wiley \& Sons, Ltd 32 (2) (2001) 139-141, https:// doi.org/10.1002/jrs.680 Available from:.

[105] A. Pavićević, S. Glumac, J. Sopta, A. Popović-Bijelić, M. Mojović, G. Bačić, Raman microspectroscopy as a biomarking tool for in vitro diagnosis of cancer: a feasibility study, Croat Med J. Croatian Medical Schools 53 (6) (2012) 551.

[106] Z. Huang, A. McWilliams, H. Lui, D.I. McLean, S. Lam, H. Zeng, Near-infrared Raman spectroscopy for optical diagnosis of lung cancer, Int. J. Cancer 107 (6) (2003) 1047-1052. Available from: http://www.ncbi.nlm.nih.gov/pubmed/ 14601068 [cited 2015 Dec 1].

[107] L. Gao, Z. Wang, F. Li, A. Hammoudi, M.J. Thrall, P.T. Cagle, et al., Differential diagnosis of lung carcinoma with coherent anti-stokes raman scattering imaging, Arch. Pathol. Lab. Med. 136 (12) (2012) 1502-1510, https://doi.org/10.5858/ arpa.2012-0238-SA\%5Cnhttp://www.ncbi.nlm.nih.gov/pubmed/23194042 Available from:

[108] L. Gao, F. Li, M.J. Thrall, Y. Yang, J. Xing, A.A. Hammoudi, et al., On-the-spot lung cancer differential diagnosis by label-free, molecular vibrational imaging and knowledge-based classification, J. Biomed. Opt. 16 (9) (2011) 96004-96010, https://doi.org/10.1117/1.3619294 Available from:.

[109] N.D. Magee, J.R. Beattie, C. Carland, R. Davis, K. McManus, I. Bradbury, et al., Raman microscopy in the diagnosis and prognosis of surgically resected nonsmall cell lung cancer, J Biomed Opt. United States 15 (2) (2010) 26015.

[110] S. Weng, X. Xu, J. Li, S.T.C. Wong, Combining deep learning and coherent antiStokes Raman scattering imaging for automated differential diagnosis of lung cancer, J Biomed Opt (2017/10/30. Society of Photo-Optical Instrumentation Engineers) 22 (10) (2017) 1-10. Available from: https://www.ncbi.nlm.nih.gov/ pubmed/29086544.

[111] X. Xu, J. Cheng, M.J. Thrall, Z. Liu, X. Wang, S.T.C. Wong, Multimodal non-linear optical imaging for label-free differentiation of lung cancerous lesions from normal and desmoplastic tissues, Biomed Opt Express (Optical Society of America) 4 (12) (2013) 2855-2868. Available from: https://www.ncbi.nlm.nih.gov/pubmed/ 24409386.

[112] L. Gao, A.A. Hammoudi, F. Li, M.J. Thrall, P.T. Cagle, Y. Chen, et al., Differential diagnosis of lung carcinoma with three-dimensional quantitative molecular vibrational imaging, J Biomed Opt. United States 17 (6) (2012) 66017.

[113] J. Park, M. Hwang, B. Choi, H. Jeong, J.-H. Jung, H.K. Kim, et al., Exosome classification by pattern analysis of surface-enhanced raman spectroscopy data for lung Cancer diagnosis, Anal Chem. United States 89 (12) (2017) 6695-6701.

[114] X. Li, T. Yang, J. Lin, Spectral analysis of human saliva for detection of lung cancer using surface-enhanced Raman spectroscopy, J Biomed Opt. United States 17 (3) (2012) 37003

[115] K. Zhang, C. Hao, Y. Huo, B. Man, C. Zhang, C. Yang, et al., Label-free diagnosis of lung cancer with tissue-slice surface-enhanced Raman spectroscopy and statistical analysis, Lasers Med Sci. England (2019).

[116] M.A. Short, S. Lam, A. McWilliams, J. Zhao, H. Lui, H. Zeng, Development and preliminary results of an endoscopic Raman probe for potential in vivo diagnosis of lung cancers, Opt Lett. United States 33 (7) (2008) 711-713.

[117] N.D. Magee, J.S. Villaumie, E.T. Marple, M. Ennis, J.S. Elborn, J.J. McGarvey, Ex vivo diagnosis of lung cancer using a Raman miniprobe, J Phys Chem B. United States 113 (23) (2009) 8137-8141.

[118] H.C. McGregor, M.A. Short, A. McWilliams, T. Shaipanich, D.N. Ionescu, J. Zhao, et al., Real-time endoscopic Raman spectroscopy for in vivo early lung cancer detection, J Biophotonics. Germany 10 (1) (2017) 98-110.

[119] M.A. Short, S. Lam, A.M. McWilliams, D.N. Ionescu, H. Zeng, Using laser Raman spectroscopy to reduce false positives of autofluorescence bronchoscopies: a pilot study, J Thorac Oncol. United States 6 (7) (2011) 1206-1214.

[120] H.C. McGregor, M.A. Short, S. Lam, T. Shaipanich, E.-L. Beaudoin, H. Zeng, Development and in vivo test of a miniature Raman probe for early cancer detection in the peripheral lung, J. Biophotonics 11 (11) (2018) e201800055. Available from: https://doi.org/10.1002/jbio.201800055 [John Wiley \& Sons, Ltd].

[121] H. Wang, S. Zhang, L. Wan, H. Sun, J. Tan, Q. Su, Screening and staging for nonsmall cell lung cancer by serum laser Raman spectroscopy, Spectrochim Acta A Mol Biomol Spectrosc. England 201 (2018) 34-38.

[122] K. Qian, Y. Wang, L. Hua, A. Chen, Y. Zhang, New method of lung cancer detection by saliva test using surface-enhanced Raman spectroscopy, Thorac cancer. Singapore 9 (11) (2018) 1556-1561.

[123] T. Yang, X. Guo, Y. Wu, H. Wang, S. Fu, Y. Wen, et al., Facile and label-free detection of lung cancer biomarker in urine by magnetically assisted surface-enhanced Raman scattering, ACS Appl Mater Interfaces. United States 6 (23) (2014) 20985-20993.

[124] L.-P. Choo-Smith, H.G.M. Edwards, H.P. Endtz, J.M. Kros, F. Heule, H. Barr, et al., Medical applications of Raman spectroscopy: from proof of principle to clinical implementation, Biopolymers. United States 67 (1) (2002) 1-9.

[125] E.B. Hanlon, R. Manoharan, T.W. Koo, K.E. Shafer, J.T. Motz, M. Fitzmaurice, et al., Prospects for in vivo Raman spectroscopy, Phys Med Biol. England 45 (2) (2000) R1-59. 